\title{
Study of Package Design for a Craft Wooden Boat Model Using Corrugated Board and Natural Extract to Prevent Termites
}

\author{
Janyut Srihirun $^{1} \&$ Benja Satongkrun ${ }^{1}$ \\ ${ }^{1}$ Faculty of Architecture, Department of Art and Design, Naresuan University, Thailand \\ Correspondence: Janyut Srihirun, Faculty of Architecture, Naresuan University, Phitsanulok 65000, Thailand. \\ Tel: 668-6514-3075. E-mail: janyuts@nu.ac.th, kaijanyut@hotmail.com
}

Received: May 3, 2017

doi:10.5539/ass.v13n8p103
Accepted: June 29, $2017 \quad$ Online Published: July 25, 2017

URL: https://doi.org/10.5539/ass.v13n8p103

\begin{abstract}
The objectives of this research were to study and design packaging, test its efficiency, and determine the satisfaction levels of consumers with the structure and graphic design of a craft wooden boat model packaging produced from corrugated board using natural extract to prevent termites. Data collection was conducted using focus groups of producers and consumers. Data was then summarized and used for the design and creation of the model packaging. Suggestions from experts were applied to improve the packaging of the craft wooden boat model; its preventive efficiency was then tested and the satisfaction of consumers was assessed. The results of the package structure test showed that bursting strength was $8.66 \mathrm{kgf} / \mathrm{cm}^{2}$, edge crush test was $3.86 \mathrm{~kg} / \mathrm{cm}$ and drop height was $762 \mathrm{~mm}$, which reaches standards ASTM D 774, ISO 3037 and ASTM D 5276, as well as helping prevent termites from biting. The size and design were portable and suitable to be displayed for sale. Concerning graphic design, a unique lined pattern narrating the story of a river of time that united the lifestyles of Thai people living along the river in the olden days, was created and combined with other design details to convey an impression of the product inside. Survey results revealed that customers were highly satisfied $(\overline{\mathrm{x}}$ $=4.09$, S.D. $=0.60)$ with the craft wooden boat model package in terms of functionality and marketing.
\end{abstract}

Keywords: Corrugated box design, Graphic design, Corrugated Board to Prevent Termites, Craft Wooden Boat Model

\section{Introduction}

Craft wooden boat models are considered important objects used to decorate homes in Thailand. They also reflect signs of marketing, worth, and travelling. A house decorated with a craft wooden boat model might provide an opportunity for an owner to travel aboard and to be wealthy. Besides, when it comes to business, it might make the owner receive significant benefits. Therefore, a craft wooden boat model has been created as a product in the program known as "One Tambon One Product (OTOP)", distributed in both internal and external Thailand (Mae Win Sub District Administration Organization, 2015).

According to an interview conducted with a wooden handicraft group in Amphur Mueang, Sukhothai province, a lack of suitable packaging for craft wooden boat model was identified as a crucial problem, because the current packaging cannot protect craft wooden boat models from damage caused by storage or transport processes. Besides, the packaging design does not attract attention from customers because the craft wooden boat models are normally wrapped in paper, covered in a plastic bag or a corrugated board used, and they also lead to damage of the craft wooden boat models during storage or transport. In addition, they can be destroyed by termites because corrugated board is made of cellulose fiber, which is a food for termites. Hence, the protection of product and packaging is considered highly important. Currently, using pesticides is a general method used to deal with the problem of termite damage (Wongkaluang \& Soranuwat, 1998). However, using chemical substances causes toxicity toward humans and the environment, and the packaging used also does not have the ability to communicate with customers and does not induce customers to purchase. These problems could be solved via designing the structure and packaging graphics to meet requirements in terms of functionality, environmental sustainability and marketing through the use of corrugated board coated with natural termite-repellant extracts combined with a suitable graphic design that can appropriately protect products during storage and transport.

According to the aforementioned reasons, the researchers realized that the integration of science and technology, 
engineering, art, design, and marketing can be combined to obtain innovative packaging for storage, transport, and retail, and to be competitive in the marketplace at a reasonable cost by designing the structure and the cushioning that concern on the engineering and marketing matters. Using the corrugated board coated with natural extracts, which was studied by our group, will be used as a choice of interest, in this case, to reduce the destruction of products caused by termites and to protect the products from being destroyed during storage and transport in both import and export cases. Additionally, the graphic on the package was designed to communicate with customers and attract attention, and can elevate an image of packaging leading to the improvement of values to products. The designed drawing represents the product inside and the uniqueness of local products. Lastly, it will be considered as a method to sustainably preserve the environment via using materials obtained by natural extracts.

\section{Objectives}

(1) To study and design packaging for a craft wooden boat model using corrugated board obtained by natural extracts

(2) To test the efficiency of packaging for craft wooden boat model using corrugated board obtained by natural extracts

(3) To evaluate the satisfaction, in terms of structure and graphics, of customers towards packaging for craft wooden boat model using corrugated board obtained by natural extracts

\section{Research Conceptual Framework}

This research framework is determined as listed below:

\subsection{Structural Package Design}

Tinnabutr (1988) stated that structural package design involves a process to determine structures, shapes, volume of materials used in the process of production and wrapping. The requirements of packaging could be concluded as

1) Protect products from being damaged

2) Ensure products inside packaging are visible

3) Convenient for transport

4) Convenient for consumption when opening the package and can be used for storage

5) Made of environmentally-friendly materials

\subsection{Graphic design}

The framework of the graphic design process proposed by Kongjareonkiet (1998) is listed below.
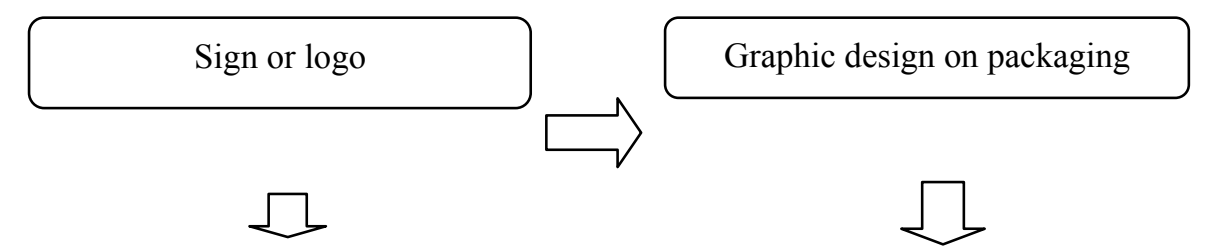

1) A sign representing a company or a product

2) One color or a variety of colors allowed

3) Representation of characteristics using alphabet or a picture

4) Visible with naked eye

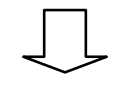

1) Beautiful and unique compared to competitors

2) Having unique characteristics

3) Having worth and inducing customers to try

4) Expressing all necessary data

\subsection{The framework of packaging efficiency testing}

The evaluation of packaging structure to protect a product inside was carried out using the standard method described below.

1) Bursting strength is the ability of paper to be resistant to a continuous force applied to a paper until the paper 
is torn. The test gives information about the toughness of the paper. This test was carried out using a Mullen tester in agreement with ASTM D774 standard (American Society for Testing and Materials, 2002).

2) Edge crush test (ECT). This test involves testing the ability of a square corrugated board to be resistant against a force applying in the direction similar to the vertical axis of the corrugated board. The force will be continuous until the corrugated board is broken or collapsed (International Organization for Standardization, 2007). The test is considered important because it gives information about the strength of the corrugated board, and was carried out using a crush tester corresponding with ISO3037 standard. This test was directly related to the Box Compression test (BCT), which can be calculated according to the equation stated by Mckee et al. (1963), referred to as $\mathrm{BCT}=5.87 \mathrm{ECT} \sqrt{\mathrm{ZH}}$, where, $\mathrm{Z}=$ perimeter of a box $(\mathrm{cm})=2(\mathrm{~L}+\mathrm{W}), \mathrm{H}=$ height of the corrugated box $(\mathrm{cm}), \mathrm{L}=$ length of a box $(\mathrm{cm})$, and $\mathrm{W}=$ width of a box $(\mathrm{cm})$.

3) The Drop test is a test to examine the ability of the sample carrying a product to be resistant against force when the sample drops on the floor, according to ASTM D5276 standard, which relates to packaging carrying products weighing less than $9.1 \mathrm{~kg}$ dropped on the floor with $762 \mathrm{~mm}$ in height. The numbers of dropping were a fixed constant (American Society for Testing and Materials, 2004).

4) To test the ability of packaging against destruction caused by termites, the coated and uncoated samples were placed in a real storehouse. The test was tracked for 1 month (the real period of time when the packaging sent to customers), and the test was evaluated by observing physical appearance of samples.

\subsection{The framework of satisfaction towards new packaging}

The evaluation processes relating to handcraft wooden boat in terms of functionality and marketing are listed below.

\section{Functionality}

1) Having efficiency in protecting a product inside

2) Convenient for carrying and taking product out

3) Consisting of part of product and able to store product conveniently

4) Be able to view the product inside

\section{Marketing}

1) Expressing unique characteristics

2) Creating memorable experiences for customers

3) Expressing benefits of products

4) Made of environmentally-friendly materials

\section{Research Scope}

The scope of this study consisted of:

\subsection{Study and design of a craft wooden boat involving:}

- Studying sources of craft wooden boat model

The interviewers were 8 persons, including 3 persons who are part of a wooden craft handcraft group, Mueang Kao, Muang Sukhothai, Sukhothai, and 5 persons who purchased handcrafted wooden boat models. The researcher chose the population based on purposive sampling.

- Sources of design and development of packaging

In order to examine and to evaluate the packaging design, the respondents were 2 experts in the field of packaging design with experience of more than 5 years, working at the Faculty of Architecture, Naresuan University, and 3 freelance designers.

- Sources of information to evaluate the satisfaction of customers toward new packaging

The population was customers and tourists interested in a handcraft wooden boat model made by the wooden handcraft group in Muang Sukhothai, Sukhothai. The researcher spent 7 days collecting questionnaire data, and each day approximately 12-15 questionnaire responses were collected. The total number of questionnaire responses collected was 100 . The purposive sampling was conducted by selecting people purchasing a craft wooden boat at a shop owned by the wooden handcraft group in Muang Sukhothai, Sukhothai. 


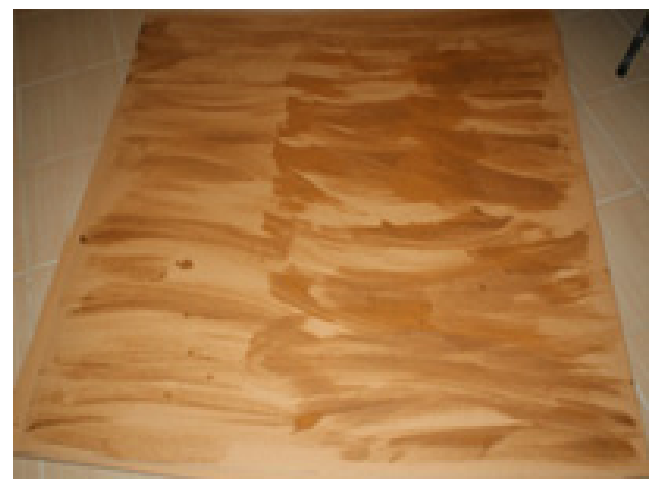

Figure 1. Coating of natural extracts onto the corrugated board via brushing

\subsection{Corrugated board made of natural extracts to protect termites}

For the production of packaging prototypes of a craft wooden boat using corrugated board obtained by natural substances to protect against termites, this research studied and developed the packaging by beginning with the extraction of a substance from Tuba root, called rotenone, which has the ability to kill insects by affecting the respiratory system. The extraction of this substance was supported by the Agricultural Technology Research Institute, Rajamangala University of Technology Lanna, Lampang campus. This substance was used to protect against termites by mixing with tapioca flour and TWEEN ${ }^{\circledR} 20$ substance in the appropriate ratio and then pasting it on the surface of the corrugated board (KA185/CA125/KA185, B Flute). The surface was allowed to dry before printing with a graphic and processed, as shown in Figure 1 (Srihirun et al., 2011).

4.3 Variables relating to efficiency testing of packaging structure and evaluation of the satisfaction of customers toward new packaging

1) Independent variables were the pattern of structure and graphic on the packaging of the five craft wooden boats including 1) China junk, 2) Thai junk, 3) Eium Chun boat, 4) Kao Chin boat, 5) row boat, as shown in Figure 3.

2) Dependent variables included:

-The efficiencies of packaging to protect the products including bursting strength, edge crush test, drop test, termites protecting test.

-The satisfaction of customers with the characteristics of packaging in terms of functionality and marketing.

\section{Research Methodology}

Research methodology can be divided into 3 steps as described in the following details.

\subsection{Study and design of handcraft packaging for the craft wooden boat}

1) Determining direction and guidelines for study and design of packaging

After investigating the fundamental data relating to physical properties of packaging, requirement of producers and customers in terms of functionality and marketing by focus group discussion, the information was used to determine the concept for the package design. The examples of question used were: 1) What is your opinion toward the old packaging used for the craft wooden boat? 2) What is the appropriate thing that you do think most appropriate for designing new packaging for the craft wooden boat?

2) Designing the structure and the graphic, and then creating a prototype of the craft wooden boat packaging. The designed model was evaluated by experts in terms of its design and graphic. After that, suggestions were concluded to develop and to create a completed model.

\subsection{Testing efficiencies of packaging structure}

To evaluate the efficiency of new packaging to protect the product inside, testing the efficiencies of packaging structure according to the framework written in title 3.3 was used.

\subsection{Evaluation of satisfaction with new packaging}

1) A questionnaire was used to investigate the satisfaction of customers toward the new packaging in terms of structure and graphic, the questionnaire used was a Likert scale, containing five scales; the first questions related to the general information of answerer, the second part contained questions about the satisfaction of customers towards new packaging, and the third one was suggestions. Before using the questionnaire, it was tested by 
experts and the reliability of the questionnaire was 0.77 . Examples of questions were: 1) Do you think the packaging effectively protects the product inside? 2) Do you think the packaging can improve the convenience, transport, and storage?

2) Using a questionnaire to evaluate the satisfaction of sample population (100 persons) to find mean and standard deviation, and then the obtained information will be analyzed and discussed via five levels of regulations, i.e. very good, good, normal, bad, and very bad. This process was used to investigate the meaning of average points. The regulation according to Likert scale (Weigel \& Newman, 1976) was:

$$
\begin{aligned}
& 4.50-5.00=\text { very good } \\
& 3.50-4.49=\text { good } \\
& 2.50-3.49=\text { normal } \\
& 1.50-2.49=\text { bad } \\
& 1.00-1.49=\text { very bad }
\end{aligned}
$$

\section{Results and Discussion}

6.1 Results of study and design of packaging for the craft wooden boat model by a corrugated board made of natural extracts to protect termites can be divided into 2 parts as follow

1) With regard to the results of studying approaches to design packaging, it was found that the product, a craft wooden boat model made by a wooden hand craft group in Amphur Mueang, Sukhothai, did not have its own packaging. The product was wrapped with a piece of newspaper before being placed in a plastic bag or a corrugated board for transport. Damage was invariably caused by the transport processes or stacking of boxes during storage because the product is fragile, easily scratched, and destroyed by termites. Besides, the packaging lacks unique characteristics. According to the focus group discussion, it was concluded that customers and the manufacturer require packaging that is strong for transportation and impact protection, able to prevent scratches, easy to carry, convenient for opening and closing, and unique. Another important consideration was that packaging must have the ability to protect the product from damage caused by termites. Additionally, the packaging should express information including logo, manufacturer address, telephone number, and offer a unique design to catch the attention of customers, both Thais and foreigners, aged more than 25 years. The mentioned requirement was in agreement with the research stated by Soodsang (2016), who claimed that the design of label and logo must be concerned with precise information and outstanding looks, be convenient to use, and have enough strength to protect the product.

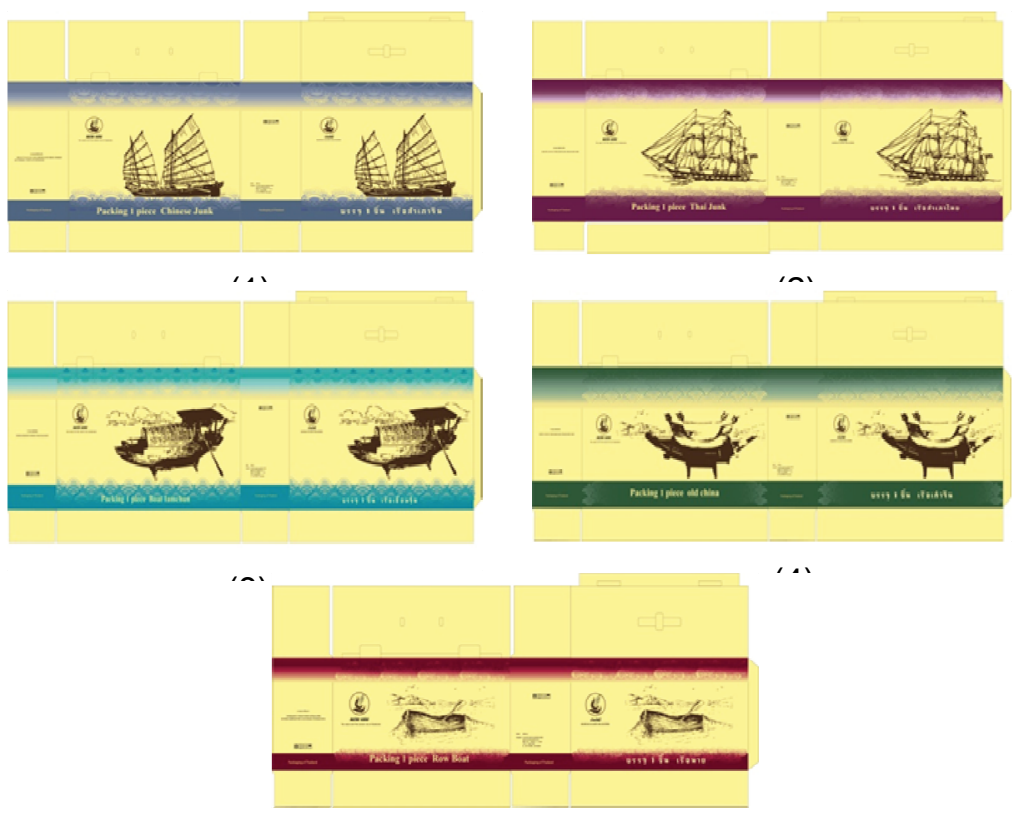

a. External p̄packaging

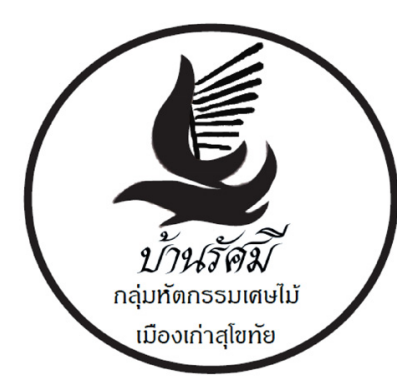

c. The Logoสินค้า

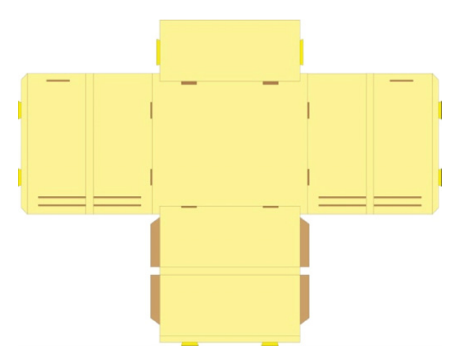

b. Interior partition

Figure 2. Pattern development and graphic drawings of external packaging and internal packaging 
2) The design process developed packaging for a craft wooden boat model using two color Flexographic printing, onto corrugated board coated with natural extracts to protect termites, in order to promote environmental conservation. Apart from the mentioned application, the package was a unique design with a carrying loop, designed in the shape of a rectangle. This design corresponded with the aim to be convenient for transport and storage, as shown in Figure 2a. The internal part of the box was designed to have a partition to absorb energy, as shown in Figure 2b. The front side of the box was designed to express a logo of product, "Ban Ratsamee" which was the original brand that had been modified. Figure $2 \mathrm{c}$ uses the font "DSN MonTaNa Regular". In terms of the name of the product, net volume is presented in Thai, and the back is written in English using "JasmineUPC Regular." The graphic can be considered simple, but gives the story of a river of time that unites the lifestyles of Thai people living along the river in the olden days. Figure 3(a)-(g) shows the image of five boat models to make the customers understand about the product inside, and they are drawn with modernized colors (natural tones). Both sides of the box express information about the address and telephone number of the manufacturer and transportation instructions. The design and the structure of this product were developed and modified corresponding with the suggestions of experts in terms of efficiency to protect the product during storage and transport. The designed package has a suitable structure which saves paper and is simple to process for packing. Moreover, the design efficiently protects the craft wooden boat model during storage and transport, and presents the product inside the package beautifully. The packaging is suitably sized and shaped to make it portable and the materials used are environmental friendly. These properties are in agreement with the idea of Tinnabutr (1988), who stated that the design of packaging structure is to determine shape, volume, and others to meet the requirement of applications, production processes, packing, storage, and transport. Besides, the packaging having suitable sizes and structures can promote the image of the product (Thackston et al., 2013).

The graphic design on the packaging is aesthetically pleasing, unique, and consistent with the product inside. The images, texts and symbols shown are appropriately placed. There is also helpful information about the product in accordance with Kongcharoenkiat's concept (1998), which stated that the graphic needs to reflect distinctiveness and illustrate characters, both Thai and English. This will encourage tourists to purchase it as a souvenir and shares details of the products, explaining meanings of the products inside, the beautiful graphic design on the packaging, the images, the texts, the certified standards and other symbols. All are organized in a suitable position consistent with criteria derived from Ahmen, Parmer \& Amin (2004), who found that components of packaging comprising colors, packaging materials and innovation are crucial factors that influence purchasing decision. This is especially the case for packaging, which needs to lay out product details in absolute clarity and in entirety.

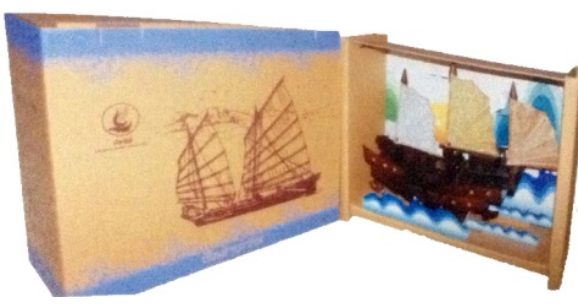

China Junk

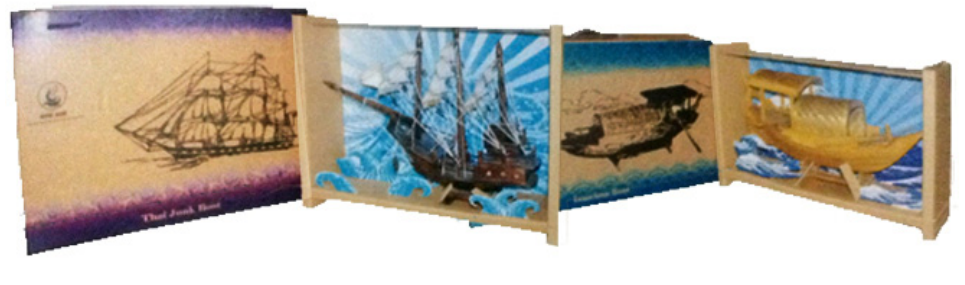

(c) Eium Chun Boat

(b) Thai Junk

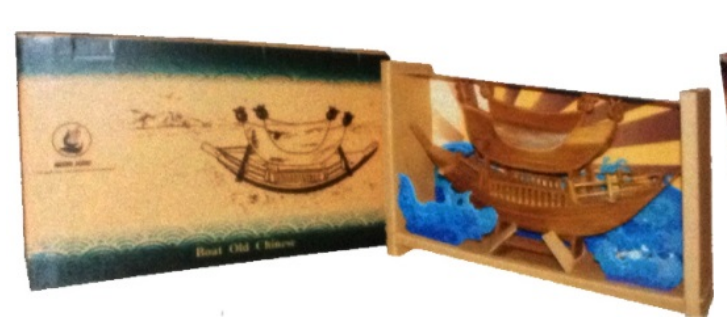

(d) Kao Chin Boat

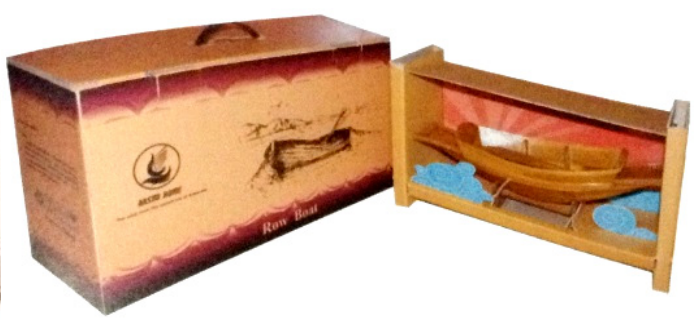

(e) Row boat 

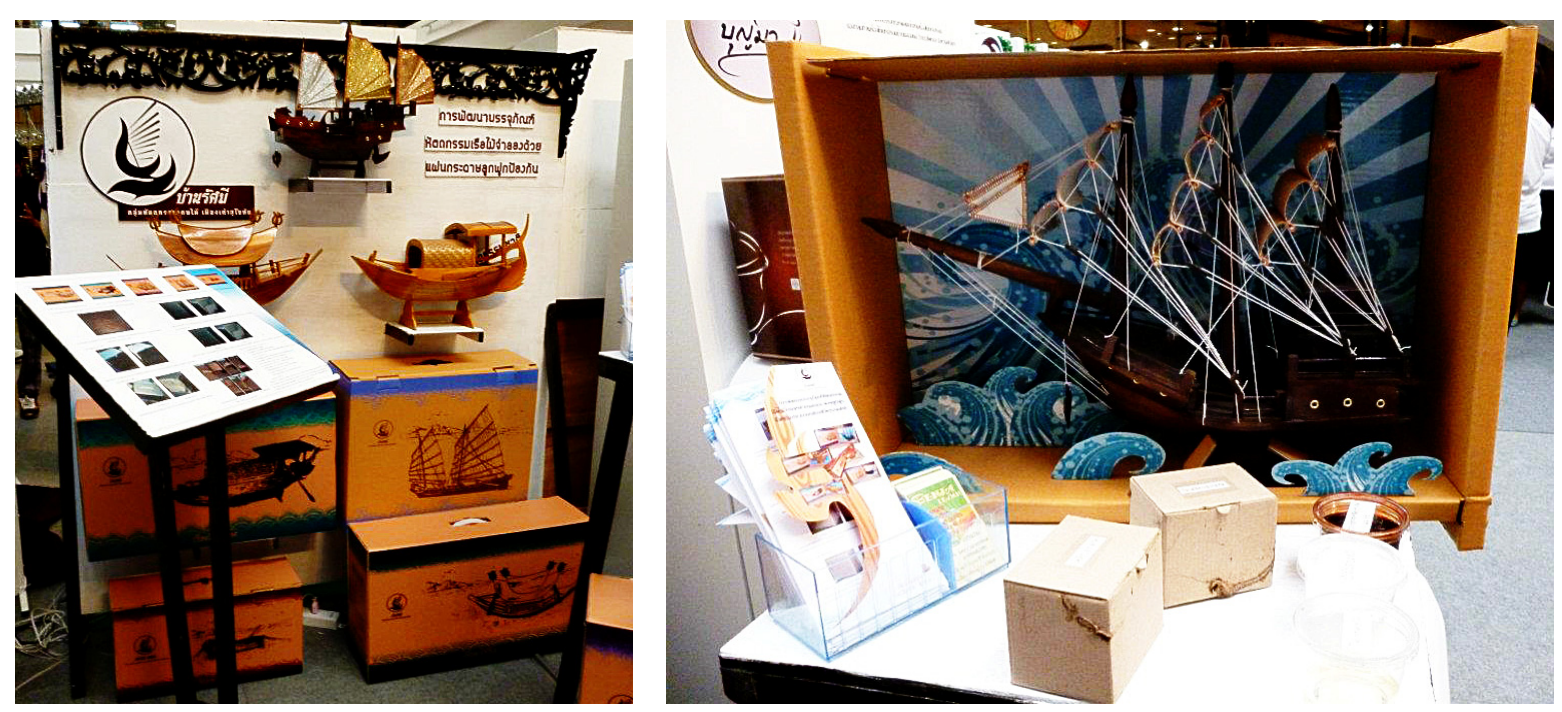

g) The exhibition

Figure 3. Prototypes of the newly designed corrugated box

\subsection{Results from the test on the effectiveness of the packaging for crafted wooden boat models}

In tests of prototype packaging effectiveness to analyze capacity to protect products by standards, the results can be categorized as follows:

1) Results reveal that the bursting strength is $8.66 \mathrm{kgf} / \mathrm{cm}^{2}$, as demonstrated in Table 1 .

Table 1. Test results for the bursting strength and ECT of the corrugated board

\begin{tabular}{ccc}
\hline Test type & $\overline{\mathrm{x}}$ & S.D. \\
\hline Bursting strength $\left(\mathrm{kgf} / \mathrm{cm}^{2}\right)$ & 8.66 & 0.10 \\
ECT $(\mathrm{kg} / \mathrm{cm})$ & 3.86 & 0.17 \\
\hline
\end{tabular}

2) The test reveals vertical compression strength (ECT) in corrugated board to be $3.86 \mathrm{~kg} / \mathrm{cm}$ as demonstrated in Table 1. Using McKee formulae, the vertical compression strength of the corrugated box is $161 \mathrm{Kg}$.

3) The drop test of corrugated box reveals that upon letting the packaging drop to the floor at a consistent height of $762 \mathrm{~mm}$ for 6 times, at a different angles and corners of the box, no damage occurred to the box.

4) Result from the effectiveness test of the package's capability against termites reveals that upon brining packaging coated and uncoated against termites back into real storage with a 1-month follow up, the box coated against termites received no termite damages after a month. This was demonstrated in Table 2.

Table 2. Result of effectiveness test against termite damages

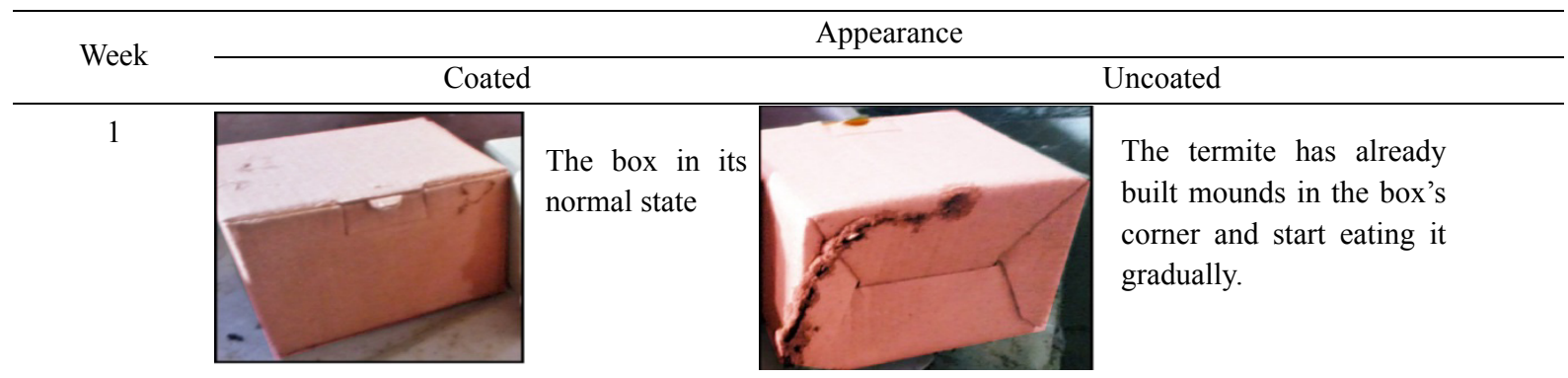


2

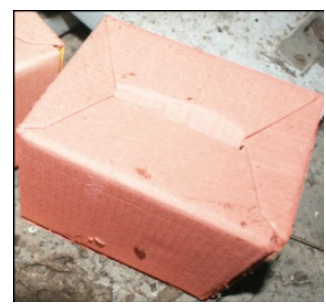

3

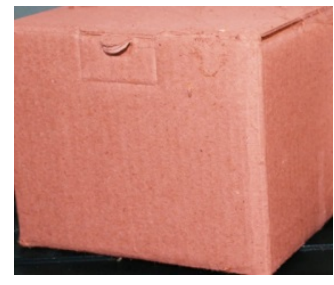

4

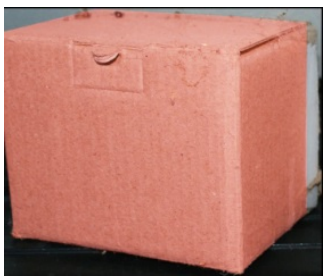

The box in its normal state

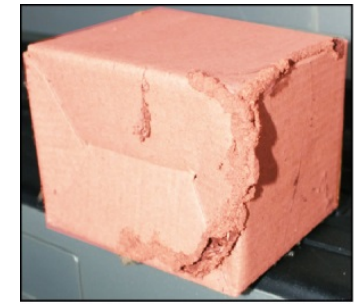

The box in its normal state

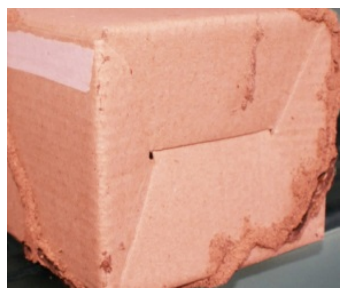

The box in its normal state

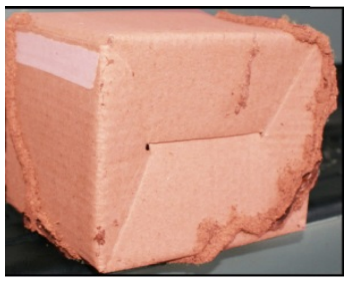

The termite has built mounds in the box, spreading to the top. More of the box is damaged than during the first week.

The termite has built mounds on the box, spreading it to all sides of the box. All sites of the papers have been damaged even more than the second week.

The termite has already burst through the box

The effectiveness of the packaging for crafted wooden boat model, which uses corrugated board coated against termites with a natural extract consists of its bursting strength in accordance with ASTM D774 standard, a result from the use of KAI85/CA123/KA185 grade board, B flute. The liner board has high toughness. The test on vertical compression strength basing on ISO 3037 standard reveals that, calculated as box strength in a stacked formation, the lowest box can handle approximately $161 \mathrm{Kg}$ without collapsing. Therefore, if the product is $4 \mathrm{Kg}$, a stack of 40 layers in storage is possible. This is due to the box shape which ensures the box circumference is consistent with McKee's theory (1963). The study stated that BCT values positively correlated with box circumference; as the circumference increases, the BCT value will increase. The design for the internal partition also acts to reinforce compression strength; it also helps protects the box against impacts from a drop at $762 \mathrm{~mm}$ according to ASTM D5276 standard. Having an internal partition influences packaging capacity to absorb impact before it hits the product. This also helps with it being kept in storage. Additionally, the packaging protects products against termite damages as shown in table 2.

6.3 Study results of customer satisfaction towards packaging for crafted wooden boat models, using corrugated board coated with natural extract against termites, with a new graphic and structural design

Table 3 illustrates customer satisfaction towards packaging for crafted wooden boat models both in functionality and marketing to be high $(\overline{\mathrm{x}}=4.09$, S.D. $=0.60)$. In terms of functionality, the efficiency in product protectiveness is very high $(\overline{\mathrm{x}}=4.71$, S.D. $=0.38)$, the convenience for its mobility, carry-on, or storage is high, $(\overline{\mathrm{x}}=4.40$, S.D. $=0.53)$, the same as for the presentation of the products inside the packaging $(\overline{\mathrm{x}}=4.43, \mathrm{~S} . \mathrm{D} .=$ $0.39)$, and the size and pattern $(\bar{x}=4.14$, S.D. $=0.53)$. The overall result on its functionality and suitability is high $(\overline{\mathrm{x}}=4.42$, S.D. $=0.46)$.

Table 3. Customer satisfaction toward the newly-designed packaging for crafted wooden boat models in both functionality and marketing

\begin{tabular}{|c|c|c|c|}
\hline \multirow[t]{2}{*}{ List } & \multicolumn{2}{|c|}{$\mathrm{n}=100$} & \multirow{2}{*}{$\begin{array}{c}\text { Satisfaction } \\
\text { level }\end{array}$} \\
\hline & $\overline{\mathrm{x}}$ & S.D. & \\
\hline \multicolumn{4}{|l|}{ 1. Functionality } \\
\hline 1.1 Effectiveness in protecting the product inside & 4.71 & 0.38 & Very high \\
\hline 1.2 Convenience in mobility, carry-on and storage & 4.40 & 0.53 & High \\
\hline 1.3 Convenient size and structure & 4.14 & 0.53 & High \\
\hline 1.4 Ability to display the product inside & 4.43 & 0.39 & High \\
\hline
\end{tabular}




\begin{tabular}{lccc}
\hline \multicolumn{1}{c}{ Overall result for functionality } & 4.42 & 0.46 & High \\
\hline 2. Marketing & & & \\
2.1 Packaging for the crafted wooden boat models is unique & 3.69 & 0.82 & High \\
2.2 Packaging for the crafted wooden boat model to be suitably beautiful with the product & 4.00 & 0.58 & High \\
2.3 Packaging for the crafted wooden boat looks valuable and of high value & 3.85 & 0.82 & High \\
2.4 Illustrate an image for social responsibility, such as using an environmentally-friendly & 3.52 & 0.76 & High \\
material & & & \\
\hline Overall result for marketing & 3.77 & 0.75 & High \\
\hline Overall score & 4.09 & 0.60 & High \\
\hline
\end{tabular}

When it comes to marketing, the packaging for the crafted wooden boat models was considered suitably beautiful for the products, and the satisfaction score is high $(\overline{\mathrm{x}}=4.00$, S.D. $=0.58)$. The score is also high for whether the packaging looks valuable and of high-worth, $(\bar{x}=3.85$, S.D. $=0.82)$, for its unique look $(\bar{x}=3.69$, S.D. $=0.82)$, and for its socially responsible image, such as using environmentally friendly products $(\overline{\mathrm{x}}=3.52$, S.D. $=0.76)$. The overall marketing result is high $(\bar{x}=3.77$, S.D. $=0.75)$. When it comes to functionality, its effectiveness in protecting the product inside has the highest satisfaction score. This is followed by a successful product display, convenience in carrying and storing it, and convenience in size and form respectively. In terms of marketing, the satisfaction score for packaging beauty suitable with the product is the highest, follows by the product's valuable and high-worth look, uniqueness, and a socially responsible image from the use of an environmentally friendly product. The sample group's criticism toward both functionality and marketing is in accordance with Sansupa (2002), which stated that the packaging must protect the product inside, mobile enough for carrying and storing, provide a display that attracts purchases and clearly show the product; on commercialization, the uniqueness, strong positive impression, clear products' benefits communication, and the use of environmentally friendly materials are crucial. This is consistent with research by Vyas (2015), who stated that packaging design components, comprising shapes, text, complementing images, quality and colors, directly influence communication of product details, which speeds up the consumer purchasing decision.

\section{Conclusions}

The handicraft group in Amphur Mueng, Sukothai do not have appropriate packaging for their crafted wooden boat models, to prevent damage both during storage and transport. This is because the products are fragile with sharp parts, and are susceptible to scratches and termite damage during storage. Furthermore, their packaging is not attractive to customers. This research designed 5 new structures, together with 5 new graphics using corrugated board coated against termites with a natural extract and assessed by experts in design. The structure and the cushioning of the package was designed using the engineering and marketing principles in combination with the use of new materials in order to receive the package with easily transportable size and shape attractive product display, including preventing shocks or damage caused by termites during storage and transport. The new graphic design is distinctive, and illustrates a story about the flow of time that integrates the livelihoods of all Thais living along the rivers in the past. This idea was combined with the packaging design linked to the product inside. The packaging structure has been tested for its effectiveness to protect the product according to ASTM D 774, ISO 3037, and ASTM D 5276, while continuing to protect against termites. Additionally, the satisfaction of customers purchasing the crafted wooden boat models with the newly designed packaging is high, both in terms of functionality and marketing attractiveness. Therefore the results from this study points out that the newly designed packaging is effective in both functionality and marketing attractiveness; it will add value to the products and creates a positive product image. Future research can continue to use corrugated board coated against termites with this natural extract to design packaging for other products, so that it can protect against termites and respond to the functional and marketing needs of producers and consumers.

\section{References}

American Society for Testing and Materials. (2002). Standard test method for bursting strength of paper: D 774/D 774M. West Conshohocken, PA: ASTM International.

American Society for Testing and Materials. (2004). Drop Test for Shipping Containers: D 5276-98. West Conshohocken, PA: ASTM International.

International Organization for Standardization. (2007). Corrugated fibreboard - Determination of edgewise crush resistance: ISO 3037:2007-03 (4th ed.). Geneva: International Organization for Standardization.

Kongcharoenkiat, P., \& Kongcharoenkiat, S. (1998). Food packaging. Bangkok: Pack mates. 
Mae-Win sub-district administrative organization. (2015). Sailboat, junk, and other types of wooden boat models. Retrieved from http://www.maewin.net/index.php?ge=view\&gen_lang=190312102644\&lang=

Mckee, R. C., Gander, J. W., \& Wachuta, J. R. (1963). Compression strength formula for corrugated boxes, Paperboard Packaging, 48(8), 149-159.

Sansupa, S. (2002). Packaging magazine. Bangkok: Thailand Institute of Science and Technology Research.

Soodsang, N. (2016). A Model Development of Thai Rice Label and Package for Heath Conscious Group of

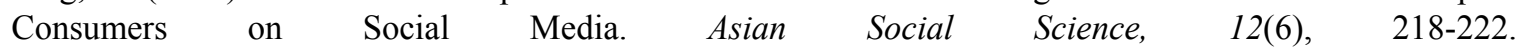
http://dx.doi.org/10.5539/ass.v12n6p217

Srihirun, J., Siripongsata T., \& Chutiseema, A. (2011). The Feasibility Study in the Prevention of Termite Destruction of Corrugated Boxes Using Natural Extracts. Proceedings of the $2^{\text {nd }}$ MJU-Phrae National Research Conference (p. 61). Phrae, Thailand: Maejo University Phrae Campus.

Tinnabutr, P. (1988). Packaging design. Bangkok: O.S Printing House.

Thackston, K., Galvarino, J., Ouzts, A., \& Pham, A. (2013). Consumer Purchasing Based on Packaging Structural Design/Product Visual Display in a Retail Environment. Retrieved from http://www.andrewd.ces.clemson.edu/ courses/cpsc412/fall11/teams/.../group7.pdf

Vyas, H. (2015). Packaging Design Elements and Users Perception: a context in fashion branding and communication. Journal of Applied Packaging Research, 7(2), 95-107.

Weigel, R. H., \& Newman, L. S. (1976). Increasing attitude-behavior correspondence by broadening the scope of the behavioral measure. Journal of Personality and Social Psychology, 33, 793-802.

Wongkaluang, J., \& Soranuwat, Y. (1998). General knowledge on termite, its prevention and extermination. Bangkok: Agency for economic research and forest produces.

\section{Copyrights}

Copyright for this article is retained by the author(s), with first publication rights granted to the journal.

This is an open-access article distributed under the terms and conditions of the Creative Commons Attribution license (http://creativecommons.org/licenses/by/4.0/). 